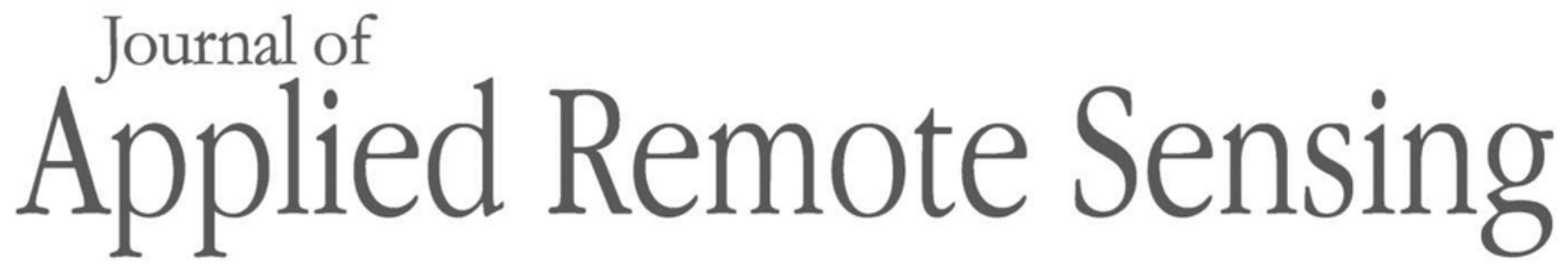

RemoteSensing.SPIEDigitalLibrary.org

\title{
Monitoring the effects of extreme drought events on forest health by Sentinel-2 imagery
}

\author{
Nicola Puletti \\ Walter Mattioli \\ Filippo Bussotti \\ Martina Pollastrini
}




\title{
Monitoring the effects of extreme drought events on forest health by Sentinel-2 imagery
}

\author{
Nicola Puletti, ${ }^{a}$ Walter Mattioli, ${ }^{\text {a,* }}$ Filippo Bussotti, ${ }^{\text {b }}$ and \\ Martina Pollastrini ${ }^{\mathrm{b}}$ \\ ${ }^{a}$ CREA, Research Centre for Forestry and Wood, Arezzo, Italy \\ ${ }^{b}$ University of Florence, Department of Agrifood Production and Environmental Sciences, \\ Firenze, Italy
}

\begin{abstract}
Global climate change is expected to result in more frequent and intense drought events, especially during the warm season. In such perspective, it is crucial to assess the forest stands vulnerability to extreme climatic events, such as drought, even for Mediterranean forest tree species, commonly considered resistant to dry spell. To test the capability of multitemporal imagery derived by Sentinel-2 (S2) in detecting the impacts of extreme drought events on forest health assessed as crown dieback, some forest stands in Tuscany (central Italy) were analyzed. Vegetation indices (VIs) and ancillary digital terrain model-derived data have been collected in 118 observational samples distributed along an ecological gradient. VIs detected a reduction of trees of photosynthetic activity in August 2017. S2 data have allowed the observation of the different response strategies of the tree species considered in this study to the extreme climatic event that occurred. The case study presented shows that S2 can be applied for monitoring climaterelated processes providing a synthetic overview of forest conditions at regional scale. (c) 2019 Society of Photo-Optical Instrumentation Engineers (SPIE) [DOI: 10.1117/1.JRS.13.020501]
\end{abstract}

Keywords: forest health; dry spell; crown dieback; Mediterranean forest stands; Copernicus program.

Paper 180824L received Oct. 12, 2018; accepted for publication Mar. 13, 2019; published online Apr. 1, 2019.

\section{Introduction}

Increases in global mean temperature mainly caused by emissions of greenhouse gases are widely acknowledged by the scientific community. Further increases are expected in the future, with higher frequency and severity of extreme drought events and heat waves ${ }^{1}$ and related impacts and damages. Extreme event is generally defined as either taking maximum values or exceedance above pre-existing high thresholds, ${ }^{2}$ thus forecasting and evaluating the consequences of these events on forest ecosystems are emerging issues for both ecologists and forest managers. ${ }^{3}$ Drought events limit the development and growth rate of plants, their strength, and then biomass accumulation and carbon sink capacity at ecosystem level. Moreover, it induces tree mortality and forest degradation. ${ }^{4}$

In the recent decades, the frequency, duration, and severity of drought have increased substantially at a global scale, ${ }^{5}$ especially in arid and semiarid regions. ${ }^{1}$ Under limited availability of soil water, the first plant response is to close stomata, ${ }^{6}$ which decreases the inflow rate into the leaves. ${ }^{7}$ Thus, forest ecosystem responses to drought and their internal adjusting mechanisms vary according to drought intensity and duration, which add uncertainty of forest responses to climatic events. ${ }^{8}$ This assumes relevance also for Mediterranean forest species, commonly considered resistant to drought events. ${ }^{9}$

Extreme drought effects on forest ecosystems have been assessed at regional, ${ }^{10}$ national, ${ }^{11,12}$ and continental scales. Distinctively, Ciais et al. ${ }^{13}$ have demonstrated a reduction of about $30 \%$ in gross primary productivity, with consequences on net source of carbon dioxide to the atmosphere and reversed the effect of four years of net ecosystem carbon sequestration. Experimental studies

*Address all correspondence to Walter Mattioli, E-mail: walter.mattioli@crea.gov.it

$1931-3195 / 2019 / \$ 25.00$ (C) 2019 SPIE 
carried out to assess the effects of such climatic events on tree growth, resilience, and mortality ${ }^{14-16}$ pointed out the need to investigate forest vulnerability and risk of dieback, especially in the Mediterranean basin, in the frame of global warming.

The assessment of forest health and tree growth is commonly carried through data collection by forest inventories and monitoring programs like the International Co-operative Program on assessment and monitoring of air pollution effects on forests. ${ }^{17}$ The main drawback of these methods, based on field plot sampling approach, is the low spatial information. On the other hand, high or very high-resolution images (e.g., WorldView-2, RapidEye satellite imagery) have been widely used for research issues, but these datasets are often expensive and not freely available. Medium-resolution imagery (particularly Landsat) was easier accessible and often cost-free for a broad majority of users, leading to many research projects. With the launch of the Sentinel-2 (S2) series, in June 2015, possibilities for research came into existence with great potential for forest monitoring because of its spectral, geometrical, and temporal resolutions. S2 combines a large swath, frequent revisit, and systematic acquisition of all land surfaces at high-spatial resolution and, with 13 spectral bands that guarantee consistent time series, showing variability in land surface conditions and minimizing any artifacts introduced by atmospheric variability. The increased swath width, along with the short revisit time, allows rapid changes to be monitored. In fact, S2 may systematically map different classes of cover, such as forest, crops, grassland, water surfaces, and artificial covers, like roads and buildings, without any need to plan a network of sample plots or point of interests investigated. Furthermore, S2 has the potential to highlight the health condition, growth, and productivity of terrestrial ecosystems at a wider scale. ${ }^{18}$

In this perspective, the objective of this study was to evaluate the capability of S2 data to detect the crown dieback in Mediterranean forest ecosystems in Tuscany (central Italy) after an extreme drought event occurred in summer 2017. Multitemporal (both intra-annual and interannual) S2 images and field data have been collected within three different forest stands, two deciduous broadleaved species, namely beech (Fagus sylvatica L.) and downy oak (Quercus pubescens Willd.), and an evergreen species, holm oak (Quercus ilex L.), in order to investigate on the response strategies of the species to the climatic event and test the capability for multitemporal monitoring climate-related processes of forest conditions at regional scale.

\section{Material and Methods}

\subsection{Case Study}

Health conditions of forest stands were analyzed by means of field survey coupled with multitemporal S2 imageries (see Sec. 2.2) and vegetation indices (VIs, see Sec. 2.3).

Observational samples (118 in total) have been carried out within three different forest stands representative of the Tuscany region (Fig. 1): beech (Fagus sylvatica L., FS, covering about $72 \mathrm{~km}^{2}$ of the forest regional area), downy oak (Quercus pubescens Willd., QP, covering about $125 \mathrm{~km}^{2}$ ), and holm oak (Quercus ilex L., QI, covering about $125 \mathrm{~km}^{2}$ ), distributed along an ecological gradient, from Mediterranean (coastal) to continental (hilly and mountain zones), from west to east part of the region. For each forest type, stands with different soil bed rock and depth, altitude, slope, and aspect have been considered to represent the different conditions in which the species can grow. Information on topographic, structural, and community compositional data have also been collected within all the observational samples. Using the information on drought-induced leaves and branches desiccation and crown defoliation, each observational sample plot has been classified as "healthy" or "unhealthy."

Considering the direct relation between air temperature with aspect and elevation, and between slope and drought, three additional topography layers (namely elevation, slope, and aspect) have also been considered. A digital terrain model at 20-m resolution was then used to create these layers.

\subsection{Sentinel Data}

S2 mission consists of two satellites, S2A launched in 2015 and S2B launched in 2017, which operate at an altitude of $705 \mathrm{~km}$ in the same orbit, phased at $180 \mathrm{deg}$ to each other and with the 


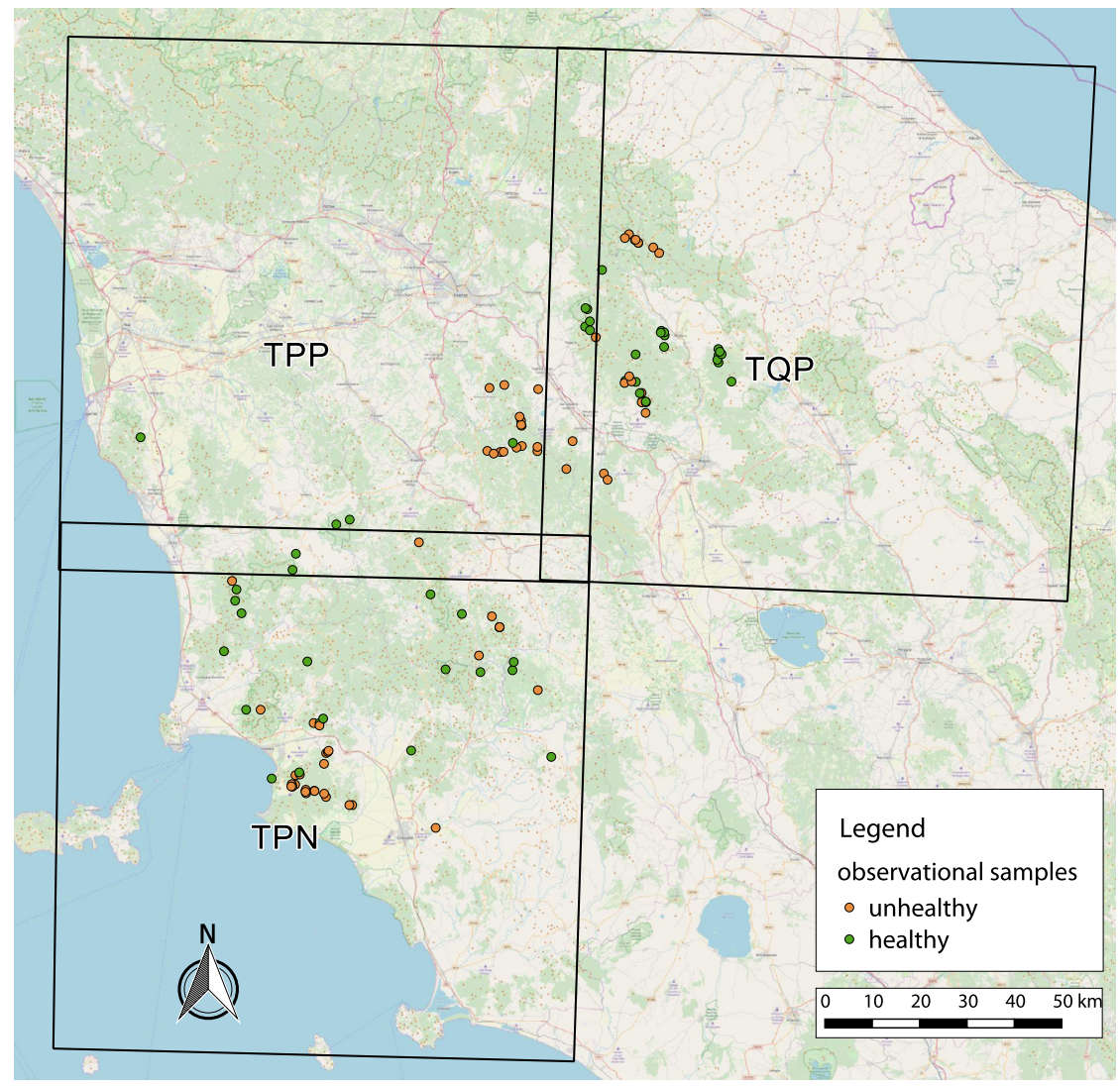

Fig. 1 The study area: squares represent the S2 tiles considered in this paper. In light green, forest cover of Tuscany region; dots show observational samples location (green: "healthy" and orange: "unhealthy").

orbit inclination of $98.5 \mathrm{deg}$. The satellites are equipped with modern multispectral highresolution scanners, 13 spectral channels, and it has resolutions of 10,20, and $60 \mathrm{~m}$ and swath width of $290 \mathrm{~km}$. The revisit time is 10 days for one satellite and 5 days for the two satellites. In this study, $30 \mathrm{~S} 2$ tiles have been processed and used for the analysis (Table 1). According to Hadjimitsis et al. ${ }^{19}$, Sen2Cor processor has been used to derive surface reflectance data (bottom of atmosphere) from S2 level 1C data, provided in the top of atmosphere reflectance. The processing was performed by sen $2 \mathrm{R}$ package. ${ }^{20}$

\subsection{Vegetation Indices}

As a proxy of the photosynthetic vegetation activity, the three more common VIs that can be generated using the four channels with 10-m spatial resolution (centered at 490, 560, 665, and $842 \mathrm{~nm}$ wavelengths; blue, green, red, and NIR bands, respectively) have been calculated: normalized difference vegetation index (NDVI), red edge NDVI (RENDVI), and simple ratio index (SRI).

\subsection{Data Analysis}

The analysis has been carried out focusing on the following different situations:

(i) each VI has been calculated for all summer months in 2017 (June, July, and August) to evaluate the drought effect on the forest tree health (crown) condition;

(ii) for each month, a comparison between observational samples classified as "healthy" and "unhealthy" has been carried out to highlight differences over calculated VIs;

(iii) FS and QI stands have been further analyzed by means of a multitemporal analysis considering the year before (2016) and after (2018) the drought event, to evaluate the presence of damages occurred before or after the extreme drought event. 
Table 1 S2 tiles used in this work.

\begin{tabular}{|c|c|c|c|c|}
\hline \multirow[b]{2}{*}{ Year } & \multirow[b]{2}{*}{ Month } & \multicolumn{3}{|c|}{ S2 tiles } \\
\hline & & TPP & TQP & TPN \\
\hline \multirow[t]{3}{*}{2016} & June & $13 r d$ & - & 28th \\
\hline & July & 18th & 18th & 18th \\
\hline & August & 28th & 28th & 28th \\
\hline \multirow[t]{3}{*}{2017} & June & $13 r d$ & $13 r d$ & $13 r d$ \\
\hline & July & 8th & 8th & 8th \\
\hline & August & 22nd & 22nd & 22nd \\
\hline \multirow[t]{5}{*}{2018} & April & 19th & 19th & 19th \\
\hline & May & 19th & - & 19th \\
\hline & June & 18th & - & 18th \\
\hline & July & 13th & 13th & 13th \\
\hline & August & 27th & 27th & 27th \\
\hline
\end{tabular}

The statistical significance of differences among VI values groups has been analyzed through $p$-values obtained from $t$-test.

\section{Results}

The applied VIs have been able to analyze the dynamics of vegetation conditions in summer 2017 within the pixels referred to the observational samples (Fig. 2). Higher mean of VI values has been registered in June and lower in August, and the analysis of S2 data highlights a

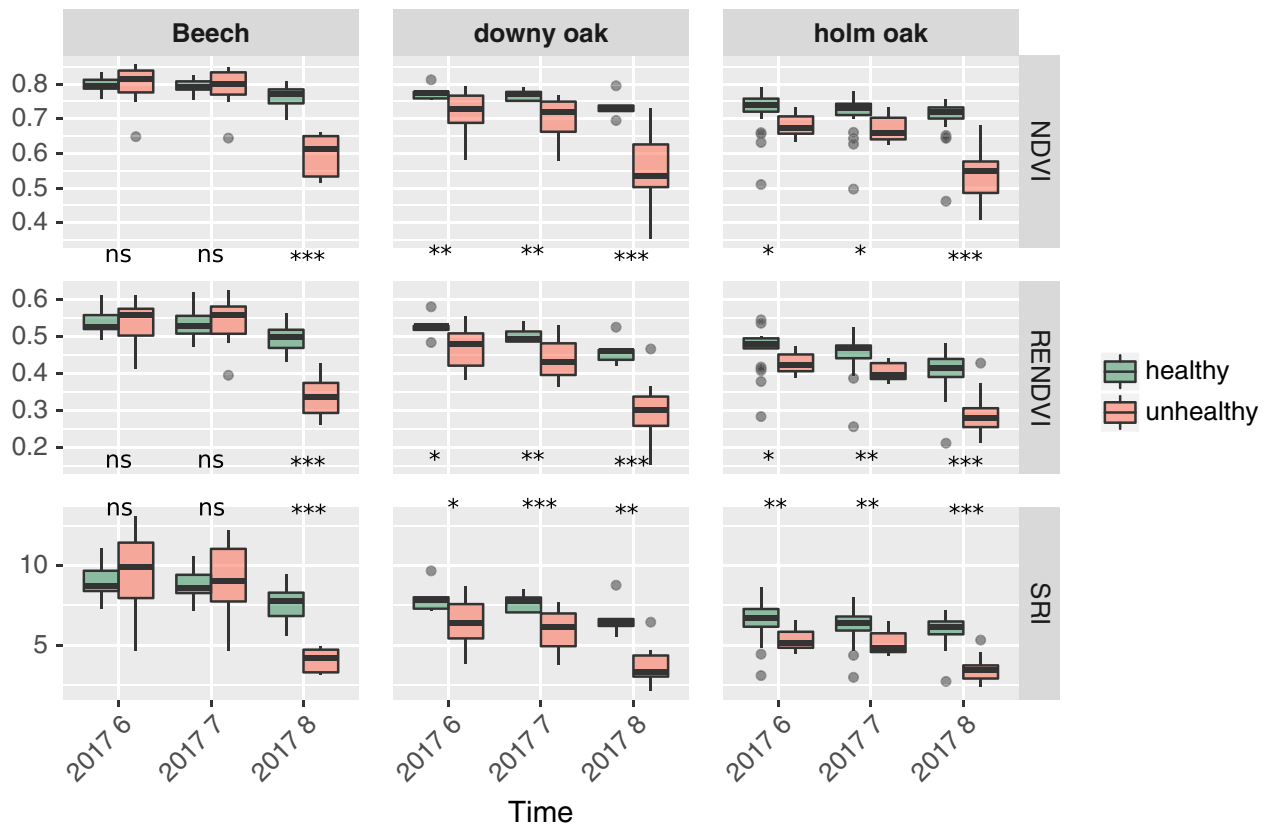

Fig. 2 Box-plot of the VI values for each forest type considered in this study during summer 2017. In August (2017-8), a significant reduction of the photosynthetic activity within observational samples classified as "unhealthy" has been observed $\left({ }^{\star \star \star} p\right.$-values $<0.001$; ${ }^{\star \star} p$-values $<0.01$; ${ }^{*} p$-values $<0.05$; ns: $p$-values $>0.05$ ). 
significant reduction ( $p$-values $<0.01$ ) of VI values in August 2017 (for both NDVI, RENDVI, and SRI), mainly for deciduous forests (FS and QP). As expected, the unhealthy stands showed a reduction of the photosynthetic activity in August 2017 (Fig. 2). VI values were statistically similar ( $p$-values $>0.5$ ) for both healthy and unhealthy stands in June and July, whereas they showed difference in August 2017 ( $p$-values $<0.01$ ).

In a further step, the photochemical properties of the studied stands in June, July, and August 2016 and, for the same period in 2018 (i.e., one year before and one after the extreme drought event considered, respectively), have been analyzed (Fig. 3). For FS forests, NDVI values registered for healthy and unhealthy stands in both July 2016, August 2016, and from April to August 2018 were similar $(p$-values $<0.01$ ). For this species, similar mean NDVI values have been measured in healthy and unhealthy stands in July (for healthy stands: $0.80 \pm 0.02$ in 2016,
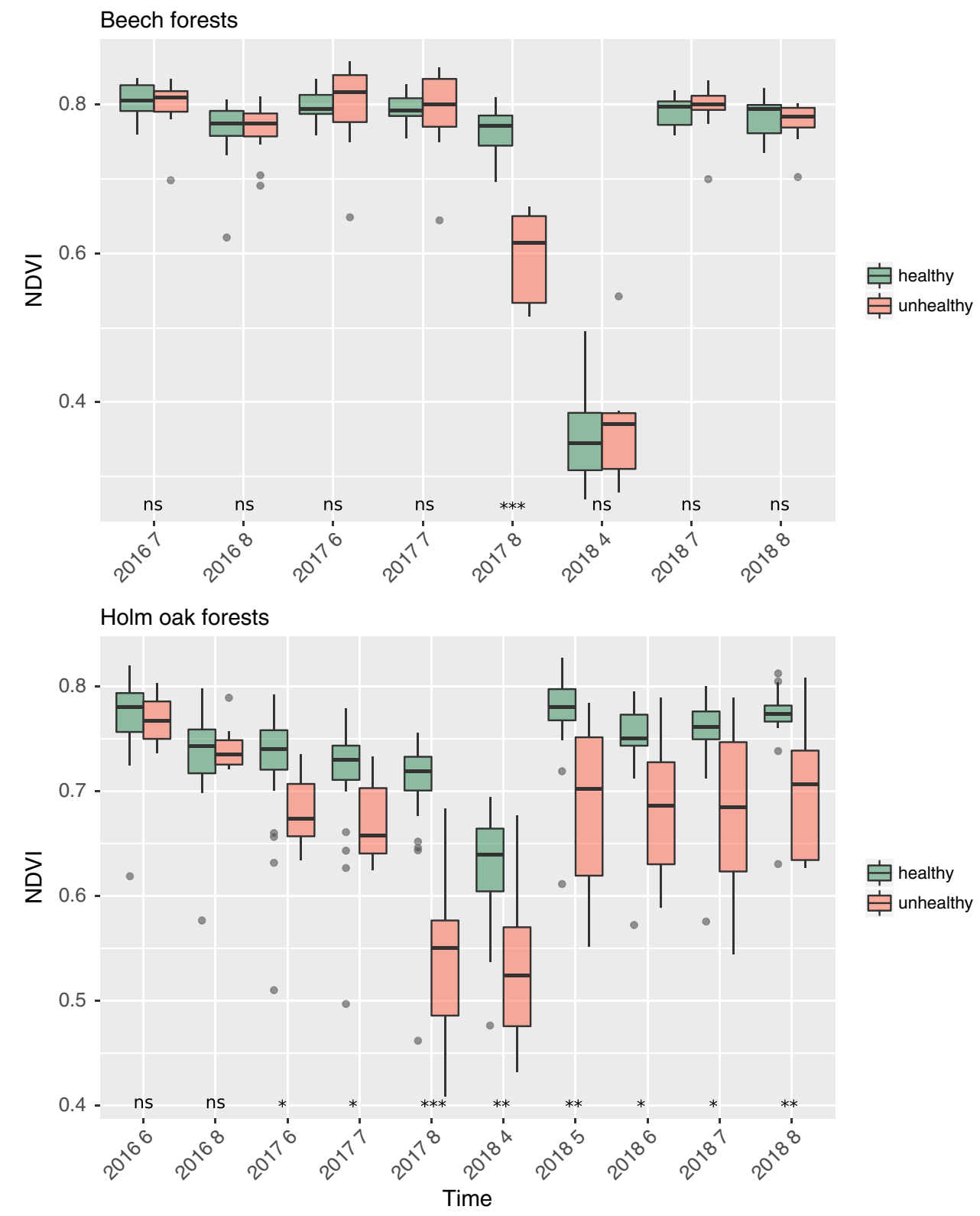

Fig. 3 Box-plot of NDVI values carried out in FS and QI forests from June 2016 (2016-6) to August 2018 (2018-8). The reduction of photosynthetic activity registered in 2018-7 did not affects FS forests because of their adaptation strategy against drought events. Eleven "unhealthy" QI stands experienced drought stress in 2017, leading to a permanent reduction of NDVI values ( ${ }^{\star \star *} p$-values $<0.001 ;{ }^{* *} p$-values $<0.01 ;{ }^{*} p$-values $<0.05$; ns: $p$-values $\left.>0.05\right)$. 
$0.79 \pm 0.02$ in 2017 , and $0.79 \pm 0.02$ in 2018; for unhealthy stands: $0.80 \pm 0.04$ in $2016,0.79 \pm$ 0.06 in 2017, and $0.79 \pm 0.06$ in 2018) and August (for healthy stands: $0.76 \pm 0.04$ in 2016, $0.76 \pm 0.03$ in 2017, and $0.78 \pm 0.02$ in 2018; for unhealthy stands: $0.76 \pm 0.04$ in $2016,0.76 \pm$ 0.03 in 2017, and $0.78 \pm 0.02$ in 2018).

Conversely, QI forests have shown similar values of mean NDVI in healthy and unhealthy stands till August 2016. Despite QP stands are dominated by broadleaved species, such as FS stands, their response to the drought event was more comparable to the one had by QI (evergreen) stands.

\section{Discussion and Conclusions}

This case study addressed the sensitivity of S2 imagery to detect extreme drought effects on tree crown health status in central Italy, comparing the response of three different forest types, characterized by two broadleaved and one evergreen tree species, typical of Mediterranean forest environments. Detecting of such effects has been based on seasonal variations of three VIs (namely NDVI, RENDVI, and SRI) in three years: 2016, 2017, and 2018. The three VIs have similar performance (Fig. 3) and can be alternatively used for operative purposes, e.g., tools for automatic detection from S2 imageries. These findings, obtained exploiting yearly VIs trajectories, have been validated by visual inspection of all 118 observational samples performed after drought event in 2018 and are consistent with phenological behavior of the examined species. For example, beech is considered a relatively drought-susceptible species, able to optimize its photosynthetic assimilation rates under mild drought conditions. This behavior became disadvantageous under severe drought events, as the one occurred in 2017, leading to desiccation damages in leaves and branches. Leaves of this species are stress-sensitive particularly in spring, during leaf emergence. ${ }^{21,22}$ However, Polle et al. ${ }^{23}$ found that mature leaves in late summer will become stress-sensitive if an extended period of drought and elevated air temperatures occurs. The anticipated reduction of tree vitality in beech mature leaves was detected by S2 images as a strong reduction of VI values in August 2017. Despite this, as pointed out by recent studies, ${ }^{24}$ an important aspect of drought tolerance in trees is their ability to recover after drought release and quickly resume full physiological activity. The analysis of S2 data confirmed, without field surveys, that beech can recover the photosynthetic activity due to a leaf mass, developed after the drought events (Fig. 3).

In parallel, as typical Mediterranean sclerophyllous species, holm oak is tolerant to short and occasional extreme events, as confirmed by VI trajectories (Fig. 3, bottom part). These recursive stresses generate morphological, genetic, and biochemical modifications at tree level that can be positive for trees, making them more resistant to future exposure to the same stress factor. ${ }^{25}$ However, the increased frequency, length, and intensity of drought events experienced in the Mediterranean basin in last two decades, with high rate of evapotranspiration and low precipitation, negatively affect the vegetation growth of holm oaks. ${ }^{26}$

Compared with other similar satellites (e.g., mainly Landsat) and considering its recent launch, the main limitation of S2 on environmental monitoring relies on historical time series analysis. ${ }^{27}$ On the other hand, the finer geometric, temporal, and spectral resolutions make S2 multitemporal data suitable to monitor drought-induced canopy damages in forest ecosystems has been demonstrated, confirming the potential of S2 satellites for applications in forestry and vegetation analysis. ${ }^{18}$

The case study presented shows that $\mathrm{S} 2$ can be applied for multitemporal monitoring climaterelated processes providing a synthetic overview of forest conditions at regional scale, and, by means of VIs, to point out different response strategies of tree species to extreme climatic events. S2-10-m spatial resolution seems to be adequate to investigate punctual phenomena, like drought-induced damages on forest stands, providing information about potential declines in vegetation health very quickly (early warning) without fieldwork.

If properly established in a web GIS application (e.g., Google Earth Engine), this kind of analysis can be readily used for forest management to detect and map the occurrence of drought-induced damages at forest stand level over wide areas. 


\section{Acknowledgments}

We would like to thank Leonardo Tonveronachi (CREA, Research Centre for Forestry and Wood) and Giovanni Iacopetti (University of Florence) for their support in field data collection.

\section{References}

1. IPCC, "Climate change 2007: the physical science basis," in Contribution of Working Group I to the Fourth Assessment. Report of the Intergovernmental Panel on Climate Change, S. Solomon et al., Eds., Cambridge University Press, Cambridge, United Kingdom/ New York, pp. 996 (2007).

2. D. B. Stephenson, "Definition, diagnosis, and origin of extreme weather and climate events," in Climate Extremes and Society, H. F. Diaz and R. J. Murnane, Eds., Cambridge University Press, Cambridge, pp. 11-23 (2008).

3. G. B. Bonan, "Forests and climate change: forcings, feedbacks, and the climate benefits of forests," Science 320(5882), 1444-1449 (2008).

4. B. Choat et al., "Global convergence in the vulnerability of forests to drought," Nature 491, 752-755 (2012).

5. A. Dai, "Drought under global warming: a review," Clim. Change 2, 45-65 (2011).

6. G. Cornic and A. Massacci, "Leaf photosynthesis under drought stress," in Photosynthesis and the Environment, N. R. Baker, Ed., Kluwer Academic Publishers, The Netherlands, pp. 347-366 (1996).

7. M. Farooq et al., "Plant drought stress: effects, mechanisms and management," Agron. Sustain. Dev. 29, 185-212 (2009).

8. D. C. Nepstad et al., "Mortality of large trees and lianas following experimental drought in an Amazonian forest," Ecology 88(9), 2259-2269 (2007).

9. F. Bastida et al., "When drought meets forest management: effects on the soil microbial community of a Holm oak forest ecosystem," Sci. Total Environ. 662, 276-286 (2019).

10. F. Lloret, J. Penuelas, and M. Estiarte, "Experimental evidence of reduced diversity of seedlings due to climate modification in a Mediterranean-type community," Global Change Biol. 10(2), 248-258 (2004).

11. F. Maselli et al., "Evaluating the effects of environmental changes on the gross primary production of Italian forests," Remote Sens. 1(4), 1108-1124 (2009).

12. G. Chirici et al., "Prediction of forest NPP in Italy by the combination of ground and remote sensing data," Eur. J. For. Res. 134(3), 453-467 (2015).

13. P. Ciais et al., "Europe-wide reduction in primary productivity caused by the heat and drought in 2003," Nature 437, 529-533 (2005).

14. G. de Dato et al., "Effects of warmer and drier climate conditions on plant composition and biomass production in a Mediterranean shrubland community," Forest 1, 39-48 (2008).

15. A. Barbeta et al., "The combined effects of a long-term experimental drought and an extreme drought on the use of plant-water sources in a Mediterranean forest," Global Change Biol. 21(3), 1213-1225 (2015).

16. D. Liu et al., "Contrasting impacts of continuous moderate drought and episodic severe droughts on the aboveground biomass increment and litterfall of three coexisting Mediterranean woody species," Global Change Biol. 21(11), 4196-4209 (2015).

17. T. Hau $\beta$ mann and R. Fischer, "The forest monitoring programme of ICP-forests-a contribution to biodiversity monitoring," in Monitoring and indicators of forest biodiversity in Europe-from ideas to operationality, M. Marchetti, Ed., Vol. 51, pp. 413-419 (2004).

18. N. Puletti, F. Chianucci, and C. Castaldi, "Use of Sentinel-2 for forest classification in Mediterranean environments," Ann. Silvicultural Res. 42(1), 32-38 (2018).

19. D. G. Hadjimitsis et al., "Atmospheric correction for satellite remotely sensed data intended for agricultural applications: impact on vegetation indices," Nat. Hazards Earth Syst. 10, 89-95 (2010).

20. L. Ranghetti and L. Busetto, "Sen2r: an R toolbox to find, download and preprocess Sentinel-2 data," Zenodo, R package version 1.0.0, http://sen2r.ranghetti.info (2018). 
21. M. Bascietto et al., "Assessing spring frost effects on beech forests in Central Apennines from remotely-sensed data," Agric. For. Meteorol. 248, 240-250 (2018).

22. S. Greco et al., "Late spring frost in Mediterranean beech forests: extended crown dieback and short-term effects on moth communities," Forests 9(7), 388 (2018).

23. A. Polle, P. Schwanz, and C. Rudolf, "Developmental and seasonal changes of stress responsiveness in beech leaves (Fagus sylvatica L.)," Plant Cell Environ. 24(8), 821-829 (2001).

24. E. E. Pflug et al., "Resilient leaf physiological response of European beech (Fagus sylvatica L.) to summer drought and drought release," Front. Plant Sci. 9, 187 (2018).

25. E. Fleta-Soriano and S. Munné-Bosch, "Stress memory and the inevitable effects of drought: a physiological perspective," Front. Plant Sci. 7, 143 (2016).

26. S. Saura-Mas, A. Bonas, and F. Lloret, "Plant community response to drought-induced canopy defoliation in a Mediterranean Quercus ilex forest," Eur. J. For. Res. 134(2), 261-272 (2015).

27. R. Chastain et al., "Empirical cross sensor comparison of Sentinel-2A and 2B MSI, Landsat-8 OLI, and Landsat-7 ETM+ top of atmosphere spectral characteristics over the conterminous United States," Rem. Sens. Environ. 221, 274-285 (2019). 